International Orthopaedics (special issue on regenerative orthopaedics)

\title{
Regenerative orthopaedics: in vitro, in vivo ... in silico
}

\author{
Liesbet Geris ${ }^{1-3}$ \\ ${ }^{1}$ Biomechanics Research Unit, University of Liège, Liège, Belgium \\ ${ }^{2}$ Prometheus, Division of Skeletal Tissue Engineering Leuven, KU Leuven, Leuven, Belgium \\ ${ }^{3}$ Biomechanics Section, KU Leuven, Leuven, Belgium
}

\begin{abstract}
In silico, defined in analogy to in vitro and in vivo as those studies that are performed on a computer, is an essential step in problem solving and product development in classical engineering fields. The use of in silico models is now slowly easing its way into medicine. In silico models are already used in orthopaedics for the planning of complicated surgeries, personalised implant design and the analysis of gait measurements. However, these in silico models often lack the simulation of the response of the biological system over time. In silico models focusing on the response of the biological systems are in full development. This review starts with an introduction into in silico models of orthopaedic processes. Special attention is paid to the classification of models according to their spatiotemporal scale (gene/protein to population) and the information they were built on (data vs hypotheses). Subsequently, the review focusses on the in silico models used in regenerative orthopaedics research. Contributions of in silico models to an enhanced understanding and optimisation of four key elements - cells, carriers, culture and clinics - are illustrated. Finally, a number of challenges are identified, related to the computational aspects but also to the integration of in silico tools in clinical practice.
\end{abstract}

\section{Introduction}

In silico is defined, in analogy to in vitro and in vivo, as those studies that are performed on a computer or via computer simulation. The in silico dimension has since long obtained a solid place in traditional engineering sectors such as chemical engineering, automobile engineering and aviation engineering. A very illustrative example of the latter is the Boeing 777 which has become famous for being the first jetliner to be 100 percent digitally designed. Throughout the design process, the airplane was "preassembled" on the computer, eliminating the need for a costly, full-scale mock-up. Furthermore, digital mechanical engineers were programmed to simulate all maintenance operations thereby allowing 
to check bottle necks that would normally only have appeared after the airplane would have been taken in service [1]. This new design process allowed to construct an airplane that met the demands of various end users (not only aviation companies but also pilots, maintenance engineers etc), significantly reduced the problems (and associated cost) during the assembly phase [2], and led to faster approval by competent authorities resulting in a fast customer uptake. Patients are not airplanes, nor cars, nor chemical plants. But the idea behind in silico medicine is similar as for any engineering sector. To use all available information, assemble a computer model and design strategies to optimize the processes under scrutiny.

In silico medicine is not new, in fact, it is already used in orthopaedics in various ways. Surgical planning software for example, taking into account the patient's anatomy through the use of medical images, allows to carefully plan a surgery beforehand, to make sure that the identified strategy is executable (in terms of access to the sites, mechanical properties of available bone grafts etc) [3] and to develop patient-specific surgical guides [4,5]. Another example is the design of custom made implants for patients in which standard procedures cannot be used [6]. A final example are the models used in the gait analysis laboratory that are more and more incorporated in diagnosis and revalidation [7]. What all the above examples of in silico orthopaedics have in common however is their static nature. They allow to assess the situation at the moment of imaging and model building but they do not provide a prediction of the evolution of the pathology or the treatment.

A wide variety of in silico models of dynamic orthopaedic processes has been and is being developed but their uptake in clinical practice is only in its infancy. This review focusses on the in silico models capturing the (spatio)temporal dynamics of orthopaedic processes (which will henceforth be denominated simply as 'in silico models' or 'models'). This review is by no means an exhaustive listing of all available in silico models in (regenerative) orthopaedics, it merely aims to provide an introduction to the vocabulary and potential applications of this rapidly evolving and promising field of research.

\section{Classification of in silico models by length scales and information content}

When discussing the wide variety of in silico models of biomedical processes, models are classified based on a specific aspect. Typical model classifications are based on length (and time) scale of the processes described in the model (from the gene/protein up to the population level) or on the information that has been used to build the model (from data-driven to hypothesis-driven). As an introduction to in silico orthopaedics in general, in this section, we will discuss both classifications and give examples. In the next section we will then use the terms introduced in this section when describing in silico models for regenerative orthopaedics. Throughout this review, a number of terms specific for in silico modelling will be used regularly. Table 1 provides the definition of some commonly used terms.

\begin{tabular}{|l|l|}
\hline Term & Definition \\
\hline Model & $\begin{array}{l}\text { A model is an abstract representation of objects or processes that explains } \\
\text { features of these objects or processes } \\
\text { Variable }\end{array}$ \\
\hline
\end{tabular}




\begin{tabular}{|c|c|}
\hline & relations \\
\hline Parameter & Parameters are quantities that have a given value \\
\hline Implementation & Translation of the mathematical model into computer code \\
\hline Mechanistic & Mechanistic refers to the mechanisms that underlie a specific behaviour \\
\hline Phenomenological & $\begin{array}{l}\text { Phenomenological refers to the observation that was made, without looking into } \\
\text { the underlying mechanisms }\end{array}$ \\
\hline Multiscale & $\begin{array}{l}\text { Multiscale models describe processes at different length or time scales within a } \\
\text { single model }\end{array}$ \\
\hline Multiphysics & $\begin{array}{l}\text { Multiphysics models describe processes that are influenced by a combination of } \\
\text { physical phenomena (e.g. elasticity and fluid flow) }\end{array}$ \\
\hline
\end{tabular}

Table 1: Definition of commonly used modeling terms.

The most widely used classification for in silico models is based on the length (and time) scale of the processes described in the model. Figure 1 shows a classical overview of various model systems working at different spatiotemporal scales. At the smallest time scales, the models looking at genes, proteins and the regulatory networks can be found. The models at this level aim to investigate amongst others the activation under various experimental conditions $[8,9]$, the complex interplay between the different biological pathways, the attractor basins of a given network or the robustness of the network (as reviewed by [10] for developmental biology). One scale higher, at the cell level, the developed models focus on a single cell or a cluster of cells in terms of its mechanical or biological behaviour (or both). Krinner et al [11] use a single cell based modelling framework (in which a single cell is represented as a spherical object with certain mechanical characteristics) to investigate growth dynamics during cell culture. By giving the cells certain biological variables, phenomena such as cell differentiation and the influence of ageing on stemness can be studied in silico [12]. Models situated at the tissue level tend to represent cells, extracellular matrix and growth factors by concentrations or densities (in weight of growth factors per volume or amount of cells per volume). A large body of literature exists describing the use of tissue level in silico models for simulation of bone biology and regeneration as reviewed in [13-15]. Typically, these models focus on a specific aspect of the fracture healing process such as mechanical loading, soluble growth factors or angiogenesis. Models focusing on angiogenesis during fracture healing often combine the cell level with the tissue level in so-called hybrid models $[16,17]$. This allows for each biological variable to be represented in a manner that is most closely corresponding to the physical reality, being densities for ECM and individual blood vessels for the angiogenesis aspects. Another level higher is the organ level. Here we look at the whole bone, for instance, how it behaves under mechanical loading or how damage is influencing its behaviour and remodelling process $[18,19]$. Fracture risk for osteoporosis patients is calculated using organ level models [20]. Expanding this view to include the whole skeleton and musculature is done in patient level models. Gait analysis models serve as an input for the prediction of bone remodelling [21] and pathology development such as osteoarthritis [22]. The models developed for one patient can subsequently be used to simulate the behaviour of an entire patient population. Applying targeted variations to the parameter sets allows to test a wide range of 'virtual patients' [23]. In silico clinical trials can then be carried out prior (or during) in vivo clinical trials [24-26], allowing for a better stratification of patients and a reduction in resources and time needed. 
As touched upon already, some models cut across these length/time scales and combine processes at multiple levels. These models are called multiscale models. Though they can be very powerful in capturing emergent behaviour (behaviour at a specific length scale caused by phenomena taking place at another length scale), they also require even more parameters (in addition to the parameters for each level, there are the parameters related to the linking of the different scales) and carefully designed implementation techniques in order to ascertain correct results from the computational point of view.
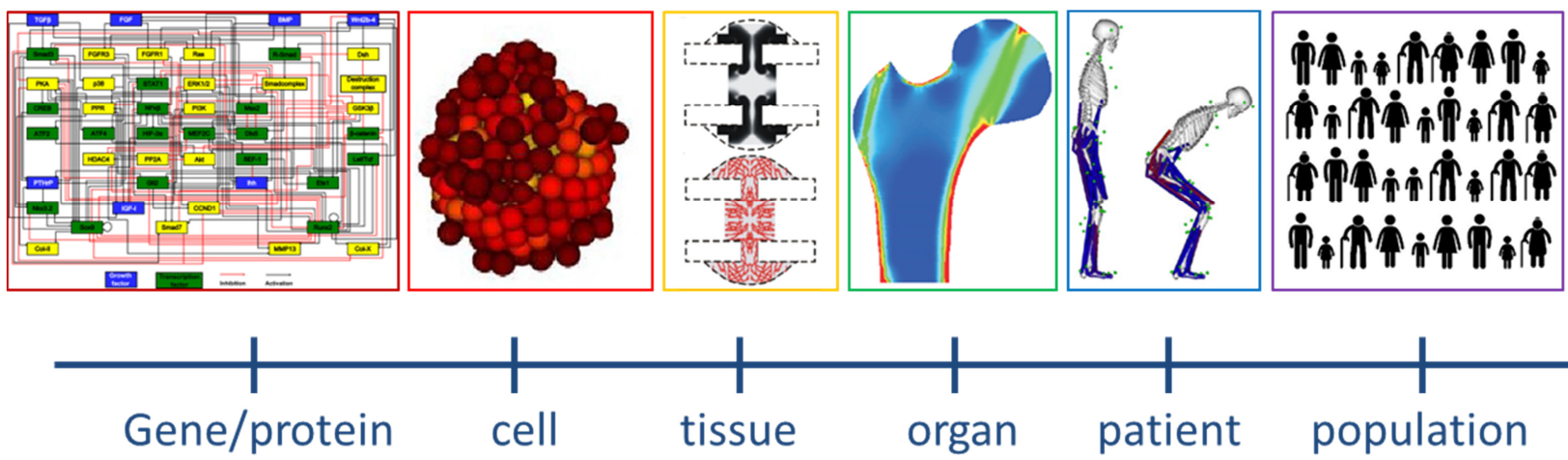

Figure 1: Classification of in silico models by length scale. Gene/protein: gene regulatory network for chondrogenic differentiation [27]. Cell: cell expansion influenced by the mechanical properties of the microbead (color scale indicates mechanical state of cell) [28]. Tissue: blood vessel (red) and bone tissue (black) formation in a murine fracture [16]. Organ: bone remodelling in proximal femur [19]. Patient: assessment of musculoskeletal system during crouching [29].

Another classification often used is based on the information content of the models (table 1). Empirical models work only with the experimental data. No mechanistic assumptions are made on how the observed phenomena came about (hence the name 'phenomenological' models). Empirical modelling is well suited to discover biomarkers in large data sets $[30,31]$ linking e.g. in vitro observations to desired in vivo behaviour [32]. in order to capture the effects of interacting pathways on the behaviour of cells, simple network models can be used. An example of such a simple network model is a Boolean model, representing variables as either 'on' (active, 1) or 'off' (inactive, 0), allowing to add a dynamical component to the models without increasing the number of parameters. Boolean network models can be used to investigate the robustness and attractor basins of the networks, and to identify missing links (additional variables that need to be added to the network in order to reproduce experimentally observed behaviour) [27,33]. What is missing in these simple network models are the complex biochemical mechanisms that are underlying the activation or inhibition as well as true spatiotemporal and quantitative information. This kind of information is present in mechanistic, hypothesis-driven models. These models start from the hypotheses that have been formulated to explain specific observations (whether from chemical, physical or biological origin). By translating these hypotheses into mathematical models and comparing the simulation results with the experimental results, the correctness and completeness of the hypotheses can be verified [34]. As these models often have a large set of parameters for which experimental values cannot always be determined, they are mainly 
used in a conceptual way. Performing in silico experiments that would be too consuming in terms of resources or time or that would ethically be unfeasible is one of the major usages for this type of models.

\begin{tabular}{|c|c|c|c|c|}
\hline \multirow[b]{2}{*}{$\begin{array}{c}\text { PHENOMENO- } \\
\text { LOGICAL, } \\
\text { DATA-DRIVEN }\end{array}$} & Type & + & - & Use \\
\hline & $\begin{array}{c}\text { Statistics } \\
\text { (clustering, PLSR) }\end{array}$ & Built on data & $\begin{array}{l}\text { No identification } \\
\text { of underlying } \\
\text { mechanistic } \\
\text { principles }\end{array}$ & $\begin{array}{c}\text { Identify } \\
\text { biomarkers }\end{array}$ \\
\hline & Boolean models & $\begin{array}{l}\text { Large number of } \\
\text { genes, proteins } \\
\text { and their } \\
\text { interaction in a } \\
\text { single network }\end{array}$ & $\begin{array}{l}\text { Absence of } \\
\text { complex } \\
\text { biochemical } \\
\text { mechanisms and } \\
\text { of true temporal } \\
\& \text { quantitative } \\
\text { information }\end{array}$ & $\begin{array}{l}\text { investigate } \\
\text { stability of } \\
\text { networks, missing } \\
\text { links and basins } \\
\text { of attraction }\end{array}$ \\
\hline $\begin{array}{c}\text { MECHANISTIC, } \\
\text { HYPOTHESIS } \\
\text { DRIVEN }\end{array}$ & $\begin{array}{l}\text { Differential } \\
\text { equations }\end{array}$ & $\begin{array}{l}\text { Quantitative and } \\
\text { time dependent } \\
\text { behaviour }\end{array}$ & $\begin{array}{l}\text { model complexity } \\
\text { (e.g. extensive } \\
\text { parameter set }\end{array}$ & $\begin{array}{l}\text { Conceptual: test } \\
\text { hypotheses and } \\
\text { perform in silico } \\
\text { experiments }\end{array}$ \\
\hline
\end{tabular}

Table 2: Classification of in silico models by the type of information they were built with.

\section{Application to regenerative orthopaedics}

In regenerative medicine in general, and regenerative orthopaedics in particular, the diamond concept has been introduced identifying four key elements for a successful therapy [35,36]: cells, carriers, growth factor and appropriate mechanical conditions. Recently the diamond concept was extended to the pentaconcept [37] stating that sufficient blood supply is also essential for a positive therapeutic result. For each of these key elements, a large body of (experimental) work can be found in the literature. For each of these elements, in silico models can increase the understanding of the biomedical processes at hand and can subsequently be used to design strategies to optimize that particular element in order to obtain the desired in vitro or in vivo outcome. For the purpose of this review we have grouped the key elements into four essential building blocks in a TE strategy, namely cells (with or without growth factors), carriers, culture (with or without growth factors or mechanics) and clinics (combining mechanics and vascularisation) (Figure 2). The models vary in length scale and information content (cfr previous section), depending on the particular research/clinical question at hand. 


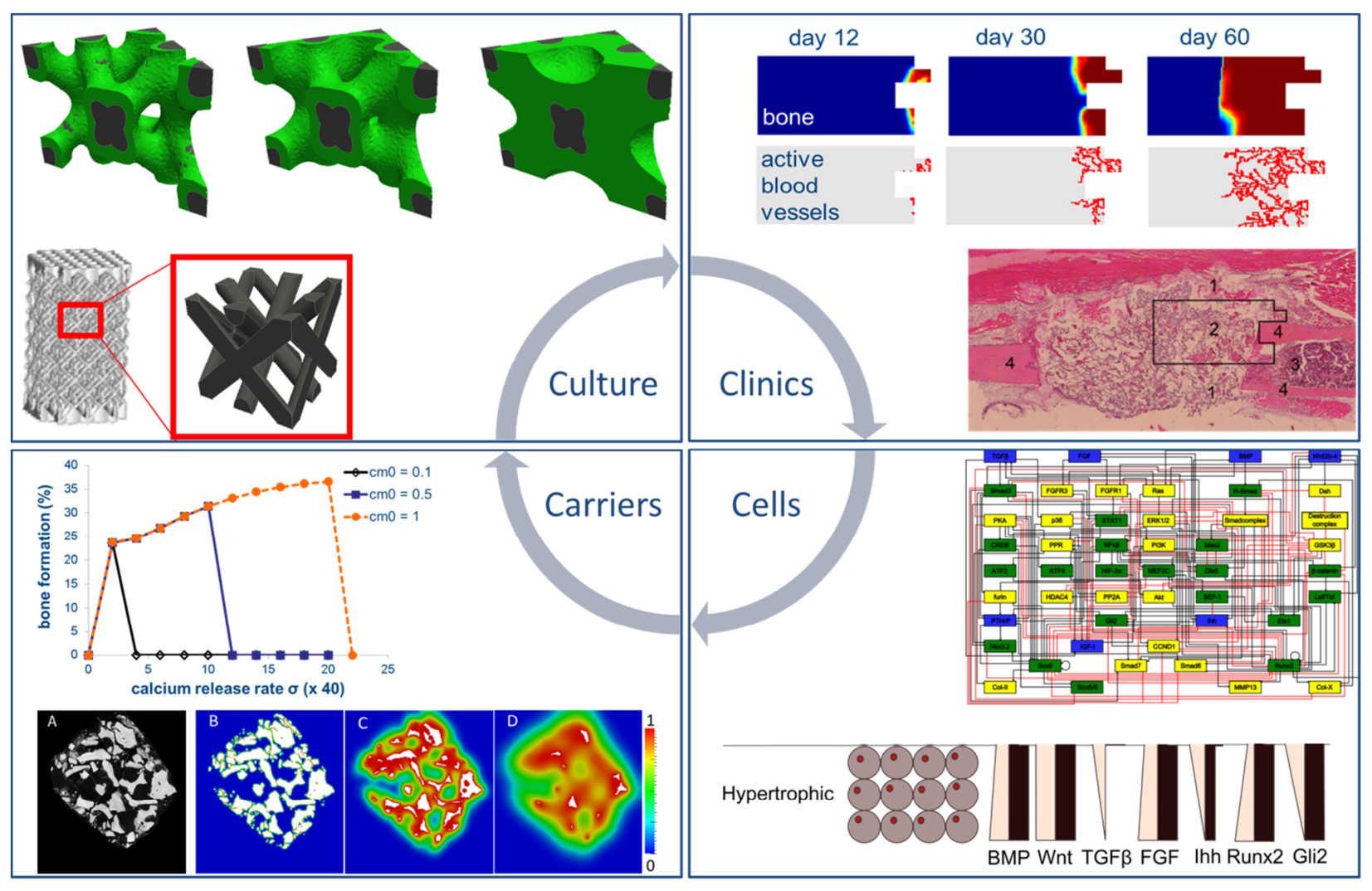

Figure 2: Classification of in silico models by their contribution to the basic building blocks of regenerative medicine. Cell: a gene regulatory network for chondrogenic differentiation is shown, along with a comparison between experimental (pale pink) and simulation (black) results for the hypertrophic phenotype [27]. Carrier: prediction of calcium dissolution from calcium phosphate based carrier (bottom, unpublished results, courtesy of $V$. Manhas) and prediction of optimal cell-carrier combinations for various initial cell densities (cm0) [38]. Culture: neotissue (green) growth in a porous titanium scaffold (grey/black) [39], clinics: simulation of blood vessel formation in a large defect in mice [17].

For the cell compartment, the main goal in regenerative orthopaedics is to obtain robust cell sources with a reproducible and predictable in vitro and in vivo behaviour. Empirical models based on extensive data sets such as the ones developed by [31,40], allow for the identification of the biological state of a cell and the distillation of a limited number of functional regulators indicative of the biological process in vitro and in vivo $[30,32,41]$. Mechanistic models using knowledge of specific relevant pathways allow to investigate the dynamics of the cell state when specific growth factors are used during cell culture $[42,43]$. Yet other models investigate the regulatory networks and the basins of attraction of specific cell states, providing insight in precise culture conditions that push or keep cells in the desired state [27,44]. An example of the latter is the work by Kerkhofs et al [27] who created a large scale literature-based Boolean model of the osteochondral regulatory network (figure 2, bottom right). Using this model the authors investigated the influence of activating or suppressing several genes in this network on the cell's capacity to progress through the endochondral ossification process. This activation or suppression can subsequently be translated into composition of culture media for in vitro cell culture. 
Models focusing on the carriers focus on the mechanical [28,45-47], chemical [48-51] and/or morphological aspects [52-55] of the carrier with the aim of understanding its influence on the behaviour of the seeded cells and subsequently optimizing its design. Smeets et al [28] use an individual cell based model to investigate the influence of the stiffness of microcarriers on the proliferation of the cells seeded onto it (figure 1, cell level). Another example is the work of Carlier et al [38] who use a mechanistic model of bone formation in calcium phosphate containing biomaterials. Based on a combination of experimental data and hypotheses put forward by experimental collaborators, the model is able to capture the different aspects of the calcium phosphate-driven bone formation process. The model is subsequently used to design combinations of cell seeding densities (or other cell properties such as growth rate) and calcium release rates yielding optimal bone formation (figure 2 , bottom left).

As reported on several occasions, bioreactor culture can be an important step in the TE product development cycle, allowing a reduction of the product variability [56-58]. A plethora of bioreactor setups are available on the market, from complete industrially developed closed systems to modular research variants. More and more the in silico models discussed above are combined with a description of the physical environment that the bioreactor presents to the TE product during the in vitro culture process (in terms of e.g. fluid flow, mechanical stimulation and mass transport). Optimization of initial cell seeding and initial cellular differentiation is predicted through the adaptation of the bioreactor protocol and scaffold morphology $[44,59,60]$, see also [61] and references within. Additionally, neotissue growth during extended culture of the TE products can be captured by multiphysics models combining a description of the physical bioreactor environment with a (mechanistic) description of cellular behaviour and matrix production [62-64]. Guyot and co-authors used a description of curvaturebased cell growth in combination with a detailed model of a perfusion bioreactor system. The combined multiphysics modelling platform has been used to optimize the location of the TE construct inside the bioreactor increasing product homogeneity and quality [56] and to screen various scaffold designs for optimal neotissue growth [39]. Once validated, these multi-physics models can become an inherent part of the bioreactor control loop providing an insight view in the TE product in culture by allowing to liaise the bioreactor sensor read-outs (e.g. pressure drop) with the biological interpretation in terms of local neotissue growth in the TE product.

Finally, the host environment (denoted clinic in figure 2) is a crucial component of the TE design strategy and the ability to predict the interaction between the host and the TE product is pivotal for many of the biological processes in regenerative orthopaedics. In silico models allow to combine knowledge on basic biology and TE product behaviour to study the effect of e.g. in vivo scaffold dissolution on local in vivo cell biology [38,54] and blood vessel formation [60,65]. Patients presenting with structurally and/or genetically challenged healing environments pose additional challenges to the TE strategy but it is most often in those patients that normal healing is impaired and thus TE solutions are required. In silico models are applied both to study the aetiology of impaired healing [17,34] and to design novel therapeutic strategies that are able to overcome the additional patient-specific hurdles [34]. These models provide an additional level of (mechanistic) understanding to the data-driven empirical models which use multi-parametric techniques to link in vitro characteristics (biomarkers) to observed in vivo behaviour (such as in classical genomics studies). 


\section{Future perspectives}

Today, the use of these dynamical models in clinical practice is still limited, however their usage as a research tool in academia and industry is growing steadily [66]. In fields such as cancer and cardiac disease computational models are directly responsible for the development of novel treatment strategies which are currently being tested in phase I and II clinical trials [42,67]. In diabetes, FDA has approved the use of computational models as valid preclinical evidence for the dossier of implantable insulin pumps [68]. Furthermore, in silico modelling is explicitly mentioned as an important tool to tackle many of the FDA's 'priorities for regulatory science for medical products' [69]. Additionally, the increasing scrutiny on the ethical aspects of biomedical research involving laboratory animals provides strong incentives for in silico research. The realisation of the $3 \mathrm{R}^{\prime} \mathrm{s}$ (reduction, refinement, replacement) is a natural consequence of the use of in silico models as an inherent part of the research pipeline. Furthermore, in silico models can assist in the translation of research findings obtained in animals to clinical opportunities in humans.

The scientific community in the field of in silico medicine is benefiting from large scale initiatives such as the Physiome [70] and the virtual physiological human [71]. The aim of these initiatives is not to develop one integrated model of a complete human being but rather to develop a framework in which models focusing on different organ systems and on different length/time scales can interact with each other. In order for this to happen, scientists active in the field of in silico medicine should agree on a set of standards [72] that will allow this interplay between different in silico models but also between in vitro, in vivo and in silico models. The trend towards personalised and precision medicine demands an ever increasing integration of all available information on the patients, ranging from life style over anatomy to genetics. The integration and interpretation of all this information can be facilitated by the use of in silico models. The vision of the virtual physiological human can have different faces depending on the users: the digital patient for clinicians [73], the digital guinea pig for researchers, personal health forecasting for patients and in silico clinical trials for industry.

As stated in the introduction, in silico medicine is already practiced in orthopaedics, however, it is mainly restricted to the mechanical aspects of the locomotor system. The simulation of biological processes, especially in regenerative orthopaedics, is in full development. In silico medicine can only reach its full potential when its development is taken in hand not only by engineers and mathematicians but also by biomedical scientists and clinicians in an interactive and integrative way. As was the case for the Boeing 777, by involving all potential users from the start of the model development, the model's clinical validation and uptake will be strongly facilitated. The ever increasing available computational power [74] will allow for the calculation of increasingly complex computational models in real-time nurturing the further exploitation of in silico models as a valuable tool in regenerative orthopaedics.

\section{Acknowledgements}


The author gratefully acknowledges funding from the European Research Council under the European Union's Seventh Framework Programme (FP/2007-2013) / ERC Grant Agreement n. 279100; from the Research Foundation - Flanders (FWO, G.0982.11), the National Fund for Scientific Research (FNRS, XX) and from the special research fund of the KU Leuven (GOA/13/016). This work is part of Prometheus, the KU Leuven R\&D division for skeletal tissue engineering. http://www.kuleuven.be/prometheus.

\section{References}

[1] http://bits.me.berkeley.edu/me39c/Spring97/Projects/b777/catia.html

[2] Glende W. (1997). The Boeing 777: a look back. AGARD FVP Symposium on The Flight Vehicle Integration Panel Symposium held in Drammen (Drammen, Norway)

[3] Gelaude F, Clijmans T, Delport H. (2011) Quantitative Computerized Assessment of the Degree of Acetabular Bone Deficiency: Total radial Acetabular Bone Loss (TrABL). Adv Orthop. 2011:494382. doi: $10.4061 / 2011 / 494382$.

[4] Audenaert E, De Smedt K, Gelaude F, Clijmans T, Pattyn C, Geebelen B. (2011) A custom-made guide for femoral component positioning in hip resurfacing arthroplasty: development and validation study. Comput Aided Surg.;16(6):304-9. doi: 10.3109/10929088.2011.613951.

[5] Clijmans T, Mommaerts M, Gelaude F, Suetens P, Sloten JV. (2008) Skull reconstruction planning transfer to the operation room by thin metallic templates: clinical results. J Craniomaxillofac Surg.;36(2):66-74. doi: 10.1016/j.jcms.2007.08.003.

[6] Gelaude F, Clijmans T, Broos PL, Lauwers B, Vander Sloten J. (2007) Computer-aided planning of reconstructive surgery of the innominate bone: automated correction proposals. Comput Aided Surg.;12(5):286-94.

[7] Baert IA, Jonkers I, Staes F, Luyten FP, Truijen S, Verschueren SM. (2013). Gait characteristics and lower limb muscle strength in women with early and established knee osteoarthritis. Clin Biomech (Bristol, Avon). 2013 Jan;28(1):40-7. doi: 10.1016/j.clinbiomech.2012.10.007

[8] Pisu M, Concas A, Cao G. (2007) A novel simulation model for stem cells differentiation. J. Biotechnol.;130(2):171-82. Epub 2007 Mar 12.

[9] Potter LK, Greller LD, Cho CR, Nuttall ME, Stroup GB, Suva LJ, Tobin FL (2005). Response to continuous and pulsatile PTH dosing: A mathematical model for parathyroid hormone receptor kinetics. Bone, 37, 159-169.

[10] Othmer HG, Painter K, Umulis D, Xue C. (2009) The Intersection of Theory and Application in Elucidating Pattern Formation in Developmental Biology. Math Model Nat Phenom. 2009 Jan 1;4(4):3-82. 
[11] Krinner A, Zscharnack M, Bader A, Drasdo D, Galle J. (2009) Impact of oxygen environment on mesenchymal stem cell expansion and chondrogenic differentiation. Cell Prolif.;42(4):471-84. doi: 10.1111/j.1365-2184.2009.00621.x.

[12] Przybilla J1, Rohlf T, Loeffler M, Galle J. (2014) Understanding epigenetic changes in aging stem cells-a computational model approach. Aging Cell.;13(2):320-8. doi: 10.1111/acel.12177.

[13] Pivonka P, Komarova SV (2010). Mathematical modeling in bone biology: From intracellular signaling to tissue mechanics. Bone, 47(2), 181-189.

[14] Pivonka P, Dunstan CR. (2012) Role of mathematical modeling in bone fracture healing. Bonekey Rep.;1:221. eCollection 2012.

[15] Geris L, Vander Sloten J, Van Oosterwyck H. (2009) In silico biology of bone modelling and remodelling: regeneration. Philos Trans A Math Phys Eng Sci. 28;367(1895):2031-53. doi: 10.1098/rsta.2008.0293.

[16] Peiffer V, Gerisch A, Vandepitte D, Van Oosterwyck H, Geris L. (2011) A hybrid bioregulatory model of angiogenesis during bone fracture healing. Biomech Model Mechanobiol. 2011 Jun;10(3):383-95. doi: 10.1007/s10237-010-0241-7

[17] Carlier A, Geris L, Bentley K, Carmeliet G, Carmeliet P, Van Oosterwyck H. (2012) MOSAIC: a multiscale model of osteogenesis and sprouting angiogenesis with lateral inhibition of endothelial cells. PLoS Comput Biol. 2012;8(10):e1002724. doi: 10.1371/journal.pcbi.1002724. Epub 2012 Oct 11.

[18] Martínez-Reina J, García-Aznar JM, Domínguez J, Doblaré M. (2008) On the role of bone damage in calcium homeostasis. J Theor Biol. 2008 Oct 7;254(3):704-12. doi: 10.1016/j.jtbi.2008.06.007.

[19] Mengoni M, Ponthot JP. An enhanced version of a bone-remodelling model based on the continuum damage mechanics theory (2014). Comput Methods Biomech Biomed Engin. PMID: 24697274.

[20] Martelli S, Taddei F, Schileo E, Cristofolini L, Rushton N, Viceconti M. (2012) Biomechanical robustness of a new proximal epiphyseal hip replacement to patient variability and surgical uncertainties: a FE study. Med Eng Phys. 2012 Mar;34(2):161-71. doi: 10.1016/j.medengphy.2011.07.006.

[21] Vahdati A, Walscharts S, Jonkers I, Garcia-Aznar JM, Vander Sloten J, van Lenthe GH. (2014) Role of subject-specific musculoskeletal loading on the prediction of bone density distribution in the proximal femur. J Mech Behav Biomed Mater. 2014 Feb;30:244-52. doi: 10.1016/j.jmbbm.2013.11.015.

[22] Pang H, Shiwalkar AP, Madormo CM, Taylor RE, Andriacchi TP, Kuhl E. (2012). Computational modeling of bone density profiles in response to gait: a subject-specific approach. Biomech Model Mechanobiol. 2012 Mar;11(3-4):379-90. doi: 10.1007/s10237-011-0318-y. 
[23] Viceconti M, Taddei F, Cristofolini L, Martelli S, Falcinelli C, Schileo E. (2012) Are spontaneous fractures possible? An example of clinical application for personalised, multiscale neuro-musculoskeletal modelling. J Biomech. 2012 Feb 2;45(3):421-6. doi: 10.1016/j.jbiomech.2011.11.048

[24] Pivonka, P., J. Zimak, et al. (2010). "Theoretical investigation of the role of the RANKRANKL- OPG system in bone remodeling." Journal of Theoretical Biology 262(2): 306-316.

[25] Pivonka P, Buenzli PR and Dunstan CR (2012). A Systems Approach to Understanding Bone Cell Interactions in Health and Disease. In: Cell Interaction, S. Gowder (Ed.), ISBN 978-953-51-0792-7, 332 pages, InTech. http://dx.doi.org/10.5772/51149

[26] Scheiner S, Pivonka P, Smith DW, Dunstan CR, Hellmich C (2014) Mathematical modeling of postmenopausal osteoporosis and its treatment by the anti-catabolic drug denosumab. Int. J. Numer. Meth. Biomed. Engng.; 30:1-27. DOI: 10.1002/cnm.2584

[27] Kerkhofs J, Roberts SJ, Luyten FP, Van Oosterwyck H, Geris L (2012) Relating the chondrocyte gene network to growth plate morphology: from genes to phenotype. PLoS One 7(4):e34729. doi: 10.1371/journal.pone.0034729.

[28] Smeets B, Odenthal T, Tijskens E, Ramon H, Van Oosterwyck H (2013) Quantifying the mechanical micro-environment during three-dimensional cell expansion on microbeads by means of individual cell-based modelling. Comput Methods Biomech Biomed Engin 16(10):1071-84. doi: 10.1080/10255842.2013.829461.

[29] Pronost N, Sandholm A. (2009) Musculoskeletal simulation: from motion capture to muscular activity in lower limb models. 3D Physiological Human Workshop (Tutorial).

[30] Platt MO, Wilder CL, Wells A, Griffith LG, Lauffenburger DA. (2009) Multipathway kinase signatures of multipotent stromal cells are predictive for osteogenic differentiation: tissue-specific stem cells. Stem Cells. 2009 Nov;27(11):2804-14. doi: 10.1002/stem.215.

[31] De Bari C, Dell'Accio F, Karystinou A, Guillot PV, Fisk NM, Jones EA, McGonagle D, Khan IM, Archer CW, Mitsiadis TA, Donaldson AN, Luyten FP, Pitzalis C. (2008) A biomarker-based mathematical model to predict bone-forming potency of human synovial and periosteal mesenchymal stem cells. Arthritis Rheum.;58(1):240-50. doi: 10.1002/art.23143.

[32] Chai YC, Roberts SJ, Desmet E, Kerckhofs G, van Gastel N, Geris L, Carmeliet G, Schrooten J, Luyten FP. (2012) Mechanisms of ectopic bone formation by human osteoprogenitor cells on CaP biomaterial carriers. Biomaterials. 2012 Apr;33(11):3127-42. doi: 10.1016/j.biomaterials.2012.01.015.

[33] Cheng X, Sun M, Socolar JE. (2013) Autonomous Boolean modelling of developmental gene regulatory networks. J R Soc Interface. 2013 Jan 6;10(78):20120574. doi: 10.1098/rsif.2012.0574. 
[34] Geris L, Reed AAC, Vander Sloten J, Simpson AHRW, Van Oosterwyck H (2010) Occurrence and Treatment of Bone Atrophic Non-Unions Investigated by an Integrative Approach. PLoS Comput Biol 6(9): e1000915. doi:10.1371/journal.pcbi.1000915

[35] Evans C (2013) Advances in Regenerative Orthopedics. Mayo Clin Proc.;88(11):1323-1339.

[36] Giannoudis PV, Einhorn TA, Marsh D. (2007) Fracture healing : the diamond concept. Injury; 38 : 3-6.

[37] Lammens J, Laumen A, Delport H, Vanlauwe J (2012) The Pentaconcept in skeletal tissue engineering: a combined approach for the repair of bone defects. Acta Orthop. Belg., 2012, 78, 569573

[38] Carlier A, Chai YC, Moesen M, Theys T, Schrooten J, Oosterwyck HV, Geris L (2011) Designing optimal calcium phosphate scaffold-cell combinations using an integrative model-based approach. Acta Biomaterialia 7(10):3573-3585. doi: 10.1016/j.actbio.2011.06.021

[39] Guyot Y, Papantoniou I, Chai YC, Van Beal S, Schrooten J, Geris L. A computational model for cell/ECM growth on 3D surfaces usingthe level set method: a bone tissue engineering case. study. Biomech Model Mechanobiol. 2014. doi:10.1007/s10237-014-0577-5

[40] Mentink A, Hulsman M, Groen N, Licht R, Dechering KJ, van der Stok J, Alves HA, Dhert WJ, van Someren EP, Reinders MJ, van Blitterswijk CA, de Boer J (2013) Predicting the therapeutic efficacy of MSC in bone tissue engineering using the molecular marker CADM1. Biomaterials 34(19):4592-601. doi: 10.1016/j.biomaterials.2013.03.001

[41] Bolander, J., Roberts, S., Eyckmans, J., Geris, L., Luyten, F. (2012). The Effect of Activating Fibroblast Growth Factor Receptor 3 Mutations on Osteogenic Differentiation and Ectopic Bone Formation by Human Periosteal Derived Cells. Journal of Tissue Science and Engineering.

[42] Schoeberl B, Pace EA, Fitzgerald JB, Harms BD, Xu L, Nie L, Linggi B, Kalra A, Paragas V, Bukhalid R, Grantcharova V, Kohli N, West KA, Leszczyniecka M,Feldhaus MJ, Kudla AJ, Nielsen UB (2009) Therapeutically targeting ErbB3: a key node in ligand-induced activation of the ErbB receptor-PI3K axis. Sci Signal 2(77):ra31. doi: 10.1126/scisignal.2000352

[43] Nicklas D, Saiz L (2013) Computational modelling of Smad-mediated negative feedback and crosstalk in the TGF- $\beta$ superfamily network. J R Soc Interface 10(86):20130363. doi: 10.1098/rsif.2013.0363.

[44] Song MJ, Dean D, Knothe Tate ML (2013) Mechanical modulation of nascent stem cell lineage commitment in tissue engineering scaffolds. Biomaterials 34(23):5766-75. doi: 10.1016/j.biomaterials.2013.04.023.

[45] Podichetty JT, Madihally SV (2014) Modeling of porous scaffold deformation induced by medium perfusion. J Biomed Mater Res B Appl Biomater 102(4):737-48. doi: 10.1002/jbm.b.33054. 
[46] Neal RA, Jean A, Park H, Wu PB, Hsiao J, Engelmayr GC Jr, Langer R, Freed LE (2013) Threedimensional elastomeric scaffolds designed with cardiac-mimetic structural and mechanical features. Tissue Eng Part A 19(5-6):793-807. doi: 10.1089/ten.tea.2012.0330.

[47] Melchels FP, Tonnarelli B, Olivares AL, Martin I, Lacroix D, Feijen J, Wendt DJ, Grijpma DW (2011) The influence of the scaffold design on the distribution of adhering cells after perfusion cell seeding. Biomaterials 32(11):2878-84. doi: 10.1016/j.biomaterials.2011.01.023.

[48] Khademi R, Mohebbi-Kalhori D, Hadjizadeh A (2014) Computational study of culture conditions and nutrient supply in a hollow membrane sheet bioreactor for large-scale bone tissue engineering. J Artif Organs 17(1):69-80. PMID: 24077884

[49] Demol J, Lambrechts D, Geris L, Schrooten J, Van Oosterwyck H (2011) Towards a quantitative understanding of oxygen tension and cell density evolution in fibrin hydrogels. Biomaterials 32(1):107-18. doi: 10.1016/j.biomaterials.2010.08.093.

[50] Pearson NC, Shipley RJ, Waters SL, Oliver JM (2013) Multiphase modelling of the influence of fluid flow and chemical concentration on tissue growth in a hollow fibre membrane bioreactor. Math Med Biol. doi: 10.1093/imammb/dqt015 PMID: 24036069

[51] Bjork JW, Tranquillo RT (2009) Transmural Flow Bioreactor for Vascular Tissue Engineering. Biotechnol Bioeng 104(6):1197-1206. doi: 10.1002/bit.22475

[52] Hollister SJ (2005) Porous scaffold design for tissue engineering. Nature Materials 4(7):518-524. doi:10.1038/nmat1421 PMID: 16003400,

[53] Saito E, Liu Y, Migneco F, Hollister SJ (2012) Strut size and surface area effects on long-term in vivo degradation in computer designed poly(L-lactic acid) three-dimensional porous scaffolds. Acta Biomaterialia 8(7):2568-2577. doi:10.1016/j.actbio.2012.03.028

[54] Byrne DP, Lacroix D, Planell JA, Kelly DJ, Prendergast PJ (2007) Simulation of tissue differentiation in a scaffold as a function of porosity, Young's modulus and dissolution rate: Application of mechanobiological models in tissue engineering. Biomaterials 28(36):5544-5554. doi:10.1016/j.biomaterials.2007.00.003 PMID: 17897712

[55] Bohner M, Baumgart F (2004) Theoretical model to determine the effects of geometrical factors on the resorption of calcium phosphate bone substitutes. Biomaterials 25(17): 3569-3582. doi:10.1016/j.biomaterials.2003.10.032 PMID: 15020131

[56] Papantoniou I, Guyot Y, Sonnaert M, Kerckhofs G, Luyten F, Geris L, Schrooten J (2014). Spatial optimization in perfusion bioreactors improves bone tissue-engineered construct quality attributes. Biotechnology and Bioengineering, accepted.

[57] Wendt D, Riboldi SA, Cioffi M, Martin I. (2009) Potential and bottlenecks of bioreactors in 3D cell culture and tissue manufacturing. Adv Mater.;21(32-33):3352-67. doi: 10.1002/adma.200802748. 
[58] Wendt D, Riboldi SA, Cioffi M, Martin I. (2009) Bioreactors in tissue engineering: scientific challenges and clinical perspectives. Adv Biochem Eng Biotechnol.;112:1-27. doi: 10.1007/978-3-540-693574_1.

[59] Adebiyi AA, Taslim ME, Crawford KD (2011) The use of computational fluid dynamic models for the optimization of cell seeding processes. Biomaterials 32(34):8753-8770. doi: 10.1016/j.biomaterials.2011.08.028

[60] Checa S, Prendergast PJ (2010) Effect of cell seeding and mechanical loading on vascularization and tissue formation inside a scaffold: A mechano-biological model using a lattice approach to simulate cell activity. Journal of Biomechanics 43(5):961-968. doi: 10.1016/j.jbiomech.2009.10.044

[61] Geris L, Gerisch A, Schugart RC (2010) Mathematical modeling in wound healing, bone regeneration and tissue engineering. Acta Biotheoretica 58(4): 355-367. doi: 10.1007/s10441-010-9112-y

[62] Bilgen B, Uygun K, Bueno EM, Sucosky P, Barabino GA (2009) Tissue growth modeling in a wavywalled bioreactor. Tissue Eng Part A, 15 (4): 761-771. doi: 10.1089/ten.tea.2008.0078

[63] Nava MM, Raimondi MT, Pietrabissa R (2013) A multiphysics 3D model of tissue growth under interstitial perfusion in a tissue-engineering bioreactor.Biomech Model Mechanobiol 12(6):11691179. doi: 10.1007/s10237-013-0473-4

[64] Bilgen B, Barabino GA. Modeling of Bioreactor Hydrodynamic Environment and Its Effects on Tissue Growth. Methods in Molecular Biology Volume 868, 2012, pp 237-255. doi:10.1007/978-1-61779764-4_14

[65] Sandino C, Checa S, Prendergast PJ, Lacroix D. Simulation of angiogenesis and cell differentiation in a CaP scaffold subjected to compressive strains using a lattice modeling approach. Biomaterials 31 (2010) 2446-2452, doi:10.1016/j.biomaterials.2009.11.063

[66] Haberman, A. (2010) Animal Models for Therapeutic Strategies. Insight Pharma Reports.

[67] http://clinicaltrials.gov/ct2/results?term=mm-121\&1Search=Search

[68] Kovatchev BP, Breton M, Man CD, Cobelli C. (2009) In silico preclinical trials: a proof of concept in closed-loop control of type 1 diabetes. J Diabetes Sci Technol.;3(1):44-55.

[69] Advancing Regulatory Science at FDA: A Strategic Plan (2011). U.S. Department Of Health And Human Services, U.S. Food And Drug Administration

[70] http://physiomeproject.org/

[71] Fenner JW, Brook B, Clapworthy G, Coveney PV, Feipel V, Gregersen H et al. (2008). The EuroPhysiome, STEP and a roadmap for the virtual physiological human. Philosophical Transactions of the Royal Society A 366 (1878): 2979-99. doi:10.1098/rsta.2008.0089. PMID 18559316. 
[72] Britten RD, Christie GR, Little C, Miller AK, Bradley C, Wu A, Yu T, Hunter P, Nielsen P. (2013) FieldML, a proposed open standard for the Physiome project for mathematical model representation. Med Biol Eng Comput.;51(11):1191-207. doi: 10.1007/s11517-013-1097-7.

[73] Díaz V, Viceconti M, Stroetmann V, Kalra D (2013) The digital patient roadmap. http:// www.digitalpatient.net/files/DP-Roadmap FINAL N.pdf

[74] Gordon E. Moore (1965) Cramming More Components onto Integrated Circuits. Electronics, 114117. 